\title{
Impact of $\beta$-blocker selectivity on long-term outcomes in congestive heart failure patients with chronic obstructive pulmonary disease
}

This article was published in the following Dove Press journal:

International Journal of COPD

5 March 2015

Number of times this article has been viewed

\section{Yoshiaki Kubota \\ Kuniya Asai \\ Erito Furuse \\ Shunichi Nakamura \\ Koji Murai \\ Yayoi Tetsuou Tsukada \\ Wataru Shimizu}

Department of Medicine (Division of Cardiology), Nippon Medical School, Bunkyo-ku, Tokyo, Japan
Correspondence: Kuniya Asai Department of Medicine (Division of Cardiology), Nippon Medical School, I-I-5, Sendagi, Bunkyo-ku, Tokyo II3-8603, Japan

$\mathrm{Tel}+8 \mid 338222131$

Fax +81358146119

Email kasai@nms.ac.jp
Background: Chronic obstructive pulmonary disease (COPD) is present in approximately one-third of all congestive heart failure (CHF) patients, and is a key cause of underprescription and underdosing of $\beta$-blockers, largely owing to concerns about precipitating respiratory deterioration. For these reasons, the aim of this study was to evaluate the impact of $\beta$-blockers on the long-term outcomes in CHF patients with COPD. In addition, we compared the effects of two different $\beta$-blockers, carvedilol and bisoprolol.

Methods: The study was a retrospective, non-randomized, single center trial. Acute decompensated HF patients with COPD were classified according to the oral drug used at discharge into $\beta$-blocker $(n=86$; carvedilol $[n=52]$ or bisoprolol $[n=34])$ and non- $\beta$-blocker groups $(n=46)$. The primary endpoint was all-cause mortality between the $\beta$-blocker and non- $\beta$-blocker groups during a mean clinical follow-up of 33.9 months. The secondary endpoints were the differences in all-cause mortality and the hospitalization rates for CHF and/or COPD exacerbation between patients receiving carvedilol and bisoprolol.

Results: The mortality rate was higher in patients without $\beta$-blockers compared with those taking $\beta$-blockers ( $\log$-rank $P=0.039$ ), and univariate analyses revealed that the use of $\beta$-blockers was the only factor significantly correlated with the mortality rate (hazard ratio: $0.41 ; 95 \%$ confidence interval: $0.17-0.99 ; P=0.047)$. Moreover, the rate of CHF and/or COPD exacerbation was higher in patients treated with carvedilol compared with bisoprolol (log-rank $P=0.033$ ). In the multivariate analysis, only a past history of COPD exacerbation significantly increased the risk of re-hospitalization due to $\mathrm{CHF}$ and/or COPD exacerbation (adjusted hazard ratio: 3.11; 95\% confidence interval: $1.47-6.61 ; P=0.003$ ).

Conclusion: These findings support the recommendations to use $\beta$-blockers in HF patients with COPD. Importantly, bisoprolol reduced the incidence of CHF and/or COPD exacerbation compared with carvedilol.

Keywords: mortality, selective $\beta$-blocker

\section{Introduction}

Chronic obstructive pulmonary disease (COPD) is present in approximately one-third of all congestive heart failure ( $\mathrm{CHF}$ ) patients, and is a key cause of underprescription and underdosing of $\beta$-blockers, owing largely to concerns about precipitating respiratory deterioration in these patients. ${ }^{1-4}$ Despite increasing evidence that $\beta$-blockers are safe and could be beneficial in patients with COPD, most large-scale CHF trials exclude patients with COPD. ${ }^{5}$ The National Institute for Health and Care Excellence and European Society of Cardiology guidelines state that COPD is not a contraindication to the use of $\beta$-blockers, and mild deterioration in pulmonary function and symptoms 
should not result in prompt discontinuation. Low-dose initiation and gradual uptitration is recommended. ${ }^{6,7}$ In addition, some studies have suggested differences in the pulmonary effects between cardioselective and non-cardioselective $\beta$-blockers, but the results of these studies are not fully conclusive $^{8-13}$ Of the $\beta$-blocker class of drugs, carvedilol is a non-selective $\beta$-adrenergic receptor (AR) blocker that also blocks $\alpha 1-\mathrm{AR}$ signaling and that has been shown to improve the state of HF patients in many studies. ${ }^{14-18}$ However, some patients are not able to continue or uptitrate the drug because of various adverse symptoms and signs, which seem to be mainly related to the $\beta 2$-AR blocking effect. On the other hand, bisoprolol, a highly selective $\beta 1$-AR blocker, has also been shown to be effective for HF patients in several studies. ${ }^{19-21}$ Although it has been reported that cardioprotective $\beta$-blockers do not worsen the pulmonary function in $\mathrm{CHF}$ patients with COPD, the impact of $\beta$-blocker selectivity on the long-term outcomes has not yet been well evaluated in these patients. In a sub-analysis of the OPTIMIZE-HF study, patients receiving non-cardioselective $\beta$-blockers were found to have a lower event rate compared to patients receiving cardioselective $\beta$-blockers. ${ }^{22}$ Thus, taking this into consideration, the aim of the present study was to evaluate the impact of $\beta$-blockers on the long-term outcomes in HF patients with COPD. In addition, we also compared the effects of carvedilol and bisoprolol in this patient population.

\section{Materials and methods}

\section{Study design}

This study was a retrospective, non-randomized, single center trial based on data collected over a 48-month period (January 1, 2009 to December 31, 2012) from 212 consecutive acute decompensated HF patients with COPD who were admitted to our hospital with HF categorized as New York Heart Association Class 3 or 4. Patients with acute coronary syndromes ( $n=34)$, including acute myocardial infarction, or with end-stage renal disease that required dialysis therapy $(n=14)$ as well as patients who did not finish the treatment course after discharge $(n=32)$ were excluded from the study. The diagnosis of HF was made on the basis of the criteria recommended in the Framingham Heart Study. ${ }^{23}$ The diagnosis of COPD was made on the basis of the global initiative for chronic obstructive lung disease criteria. ${ }^{24}$ At the time of registration, the COPD of all patients was in the stable phase. Finally, of the identified 212 patients, 132 met all inclusion criteria and were enrolled in this study.

The patients were divided into two groups according to the agents administered after admission and followed-up for a mean period of 33.9 months. The first group was treated without any $\beta$-blockers (non- $\beta$-blocker group, $n=46$ ), whereas the second group was administered $\beta$-blockers before discharge ( $\beta$-blocker group, $n=86$; carvedilol $[n=52]$ or bisoprolol $[n=34])$. After discharge, the patients continued treatment with either carvedilol or bisoprolol, with the dose being carefully increased to tolerance. The subjects were followed-up at intervals of 1-2 months in the outpatient department of our hospital from January 2009 through December 2013. The patients' health status was checked during each follow-up, and was recorded using electronic clinical records; furthermore, all-cause death and hospitalization due to $\mathrm{CHF}$ and/or COPD exacerbation were also verified using these electronic clinical records.

This retrospective study was conducted using data from a large university hospital. The protocol used complies with the Declaration of Helsinki and was approved by our Institutional Ethics Committee, which waived the need for patient consent because of the retrospective nature of the study.

\section{Relevant factors}

The heart rate (HR) and systolic blood pressure (SBP) were measured at rest, simultaneously with the electrocardiogram measurements. Height and weight were measured at the time of discharge, and the body mass index $\left(\mathrm{kg} / \mathrm{m}^{2}\right)$ was calculated as an index of obesity. Hypertension was defined as an SBP of $140 \mathrm{mmHg}$ or greater, a diastolic blood pressure of $90 \mathrm{mmHg}$ or greater, or the current use of antihypertensive agents. Chronic kidney disease was defined as a glomerular filtration rate $(\mathrm{GFR}) \leq 60 \mathrm{~mL} / \mathrm{min} / 1.73 \mathrm{~m}^{2}$. The GFR was estimated using the simplified prediction equation derived from the Modification of Diet in a Renal Disease study. ${ }^{25}$ During each echocardiographic study, the left ventricular ejection fraction (LVEF) was calculated using the modified Simpson's method. The tricuspid regurgitation velocity was obtained by continuous wave Doppler from the right ventricular inflow or the apical four-chamber view position. The tricuspid regurgitation pressure gradient (TRPG) was calculated as follows: $\mathrm{TRPG}=4 \times$ tricuspid regurgitation velocity. ${ }^{2}$ Clinical data were obtained just prior to discharge when the hemodynamic conditions of the patients had stabilized. Twelve months after the treatment initiation, all parameters were re-measured and compared with the initial data.

The primary endpoint was the differences in all-cause mortality between the $\beta$-blocker use and non-use groups during the mean clinical follow-up of 33.9 months. The secondary endpoints were the differences in composite events, including the all-cause mortality and hospitalization rates for 
CHF and/or COPD exacerbation, between patients receiving carvedilol and bisoprolol.

\section{Statistical analysis}

The SPSS software package Version 20.0 (IBM Corporation, Armonk, NY, USA) was used for the statistical analyses. All continuous values are expressed as means \pm standard deviations, and data of categorical variables are expressed as the number and percentage of patients. Survival and cardiac event-free curves were created using the Kaplan-Meier method, and differences in the survival and cardiac event-free rates among the groups were analyzed using the log-rank test. The relative risks in each group were calculated using Cox regression analyses, and $P$-values of less than 0.05 were considered statistically significant.

\section{Results}

We divided the patients into two groups according to whether a $\beta$-blocker was prescribed at discharge or not $(\beta$-blocker group, $\mathrm{n}=86$; non- $\beta$-blocker group, $\mathrm{n}=46$ ). The baseline characteristics of the patients are shown in Table 1 . There were no significant differences between the two groups in terms of age, sex, prevalence of hypertension, atrial fibrillation, chronic kidney disease or ischemic heart disease, brain natriuretic peptide (BNP) levels, forced expiratory volume in 1 second $\left(\mathrm{FEV}_{1}\right)$, or medical treatment at the time of discharge. However, patients not receiving $\beta$-blockers had a significantly higher HR at the 1-year follow-up compared with patients receiving $\beta$-blockers. In the $\beta$-blocker group, 52 patients (60.5\%; mean dose: $6.69 \mathrm{mg} /$ day) received carvedilol at discharge, whereas 34 patients (39.5\%; mean dose: $2.96 \mathrm{mg}$ / day) received bisoprolol. Regarding the different $\beta$-blockers, the clinical characteristics, excluding the HR and LVEF, did not significantly differ between the carvedilol and bisoprolol groups (Table 1). Higher HR and ejection fraction (EF) were observed in the patients receiving bisoprolol. The mean baseline $\mathrm{FEV}_{1}$ values were $1.70 \mathrm{~L}$ and $1.52 \mathrm{~L}$ in patients receiving carvedilol and bisoprolol, respectively $(P=0.344)$.

\section{Clinical outcomes}

During the mean follow-up period of 33.9 months, the primary endpoint event (all-cause mortality) occurred in 9 patients $(10.5 \%)$ in the $\beta$-blocker group and 12 patients $(26.1 \%)$ in the non- $\beta$-blocker group (log-rank $P=0.039)$ (Figure 1). $\beta$-blocker therapy significantly reduced the risk of all-cause death in the univariate analysis (unadjusted hazard ratio [HR]: $0.41 ; 95 \%$ confidence interval [CI]: 0.17-0.99; $P=0.047$ ) (Table 2). However, no significant association was observed between $\beta$-blocker use and all-cause mortality in the multivariate analysis (Table 2). Evaluation of the causes of death revealed that in the non- $\beta$-blocker group, six, three, two, and one patients died of infection-unrelated COPD exacerbation, COPD exacerbation, sudden cardiac death, and acute HF, respectively. In the $\beta$-blocker group,

Table I Clinical characteristics of the study population

\begin{tabular}{|c|c|c|c|c|c|c|}
\hline Variables & $\begin{array}{l}\beta \text {-blocker use } \\
(n=86)\end{array}$ & $\begin{array}{l}\text { No } \beta \text {-blocker } \\
(n=46)\end{array}$ & $P$-value & $\begin{array}{l}\text { Carvedilol } \\
(n=52)\end{array}$ & $\begin{array}{l}\text { Bisoprolol } \\
(n=34)\end{array}$ & P-value \\
\hline Age (years) & $78.5 \pm .6$ & $79.5 \pm 9.2$ & 0.513 & $78.2 \pm 8.2$ & $79.1 \pm 6.5$ & 0.615 \\
\hline Male sex (\%) & 90.9 & 78.6 & 0.060 & 91.6 & 89.7 & 0.770 \\
\hline $\mathrm{BMI}\left(\mathrm{kg} / \mathrm{m}^{2}\right)$ & $20.9 \pm 3.8$ & $20.4 \pm 3.3$ & 0.502 & $21.2 \pm 3.1$ & $20.5 \pm 4.6$ & 0.403 \\
\hline $\mathrm{SBP}(\mathrm{mmHg})$ & $123.0 \pm 19.5$ & $129.5 \pm 27.3$ & 0.207 & $122.5 \pm 16.8$ & $123.5 \pm 17.7$ & 0.863 \\
\hline HR (bpm, baseline) & $80.0 \pm 11.9$ & $86.0 \pm 18.1$ & 0.183 & $75.9 \pm 13.3$ & $84.1 \pm 10.5$ & 0.048 \\
\hline HR (bpm, at I year) & $70.4 \pm 10.1$ & $85.0 \pm 14.1$ & 0.023 & $70.6 \pm 9.7$ & $70.3 \pm 10.3$ & 0.909 \\
\hline IHD (\%) & 38.1 & 34.2 & 0.445 & 44.4 & 31.8 & 0.349 \\
\hline Hypertension (\%) & 62.3 & 52.6 & 0.348 & 60.0 & 66.7 & 0.617 \\
\hline $\mathrm{AF}(\%)$ & 43.3 & 58.8 & 0.152 & 42.5 & 44.1 & 0.857 \\
\hline CKD (\%) & 64.1 & 50.0 & 0.290 & 68.0 & 57.1 & 0.511 \\
\hline $\mathrm{EF}(\%)$ & $45.8 \pm 18.7$ & $45.2 \pm 17.7$ & 0.323 & $38.2 \pm 15.1$ & $54.3 \pm 16.5$ & 0.002 \\
\hline TRPG (mmHg) & $38.0 \pm 21.5$ & $36.4 \pm 11.9$ & 0.835 & $32.2 \pm 15.2$ & $43.9 \pm 27.6$ & 0.485 \\
\hline BNP (pg/mL) & $307.3 \pm 242$ & $306.1 \pm 229$ & 0.056 & $300.9 \pm 182$ & $313.7 \pm 292$ & 0.850 \\
\hline $\mathrm{FEV}_{\text {, }}(L$, baseline $)$ & $1.6 \mathrm{I} \pm 0.57$ & $|.53 \pm 0.6|$ & 0.694 & $1.70 \pm 0.56$ & $1.52 \pm 0.58$ & 0.344 \\
\hline GOLD 3,4 (\%) & 30.9 & 37.0 & 0.589 & 25.7 & 36.9 & 0.400 \\
\hline ACE-I or ARB (\%) & 70.3 & 67.6 & 0.562 & 80.6 & 60.0 & 0.099 \\
\hline Inhaled tiotropium (\%) & 35.9 & 37.8 & 0.659 & 29.7 & 42.1 & 0.364 \\
\hline
\end{tabular}

Note: Values are presented as means $\pm S D$, unless otherwise specified.

Abbreviations: BMI, body mass index; SBP, systolic blood pressure; HR, heart rate; IHD, ischemic heart disease; AF, atrial fibrillation; CKD, chronic kidney disease; EF, ejection fraction; TRPG, tricuspid regurgitation pressure gradient; BNP, brain natriuretic peptide; FEV , forced expiratory volume in I second; GOLD, global initiative for chronic obstructive lung disease; ACE-I, angiotensin converting enzyme inhibitor; ARB, angiotensin II receptor blocker. 


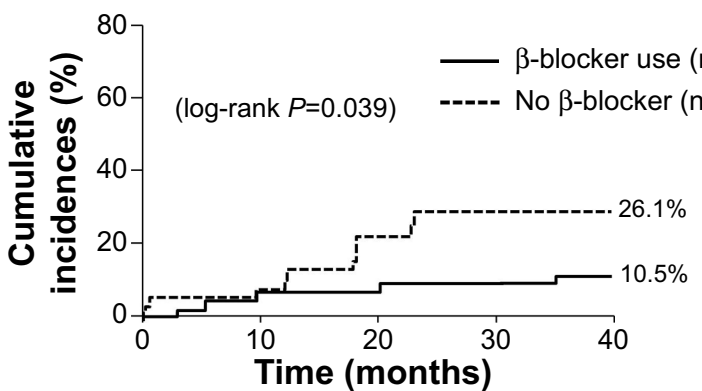

$\begin{array}{llllll}\text { B-blocker use } & 86 & 84 & 82 & 79 & 77 \\ \text { No } \beta \text {-blocker } & 46 & 44 & 36 & 34 & 34\end{array}$

Figure I Cumulative incidence of all-cause death

Note: During the mean follow-up period of 33.9 months, the mortality was higher in heart failure and COPD patients treated without vs with $\beta$-blockers (log-rank $P=0.039$ ).

Abbreviation: COPD, chronic obstructive pulmonary disease.

three, two, two, and two patients died of infection-unrelated COPD exacerbation, COPD exacerbation, sudden cardiac death, and acute HF, respectively. The percentages of each cause of death did not significantly differ between the two treatment groups.

The secondary endpoint events occurred in 35 patients $(67.3 \%)$ in the carvedilol group and 9 patients $(26.5 \%)$ in the bisoprolol group (log-rank $P=0.112$ ) (Figure 2). CHF and/or COPD exacerbation occurred in 29 patients $(55.8 \%)$ in the carvedilol group and 6 patients (17.6\%) in the bisoprolol group (log-rank $P=0.033$ ) (Figure 3 ). The rate of all-cause death did not significantly differ between the two groups ( $11.5 \%$ vs $8.8 \%$ in the carvedilol vs bisoprolol groups, data not shown). Univariate Cox regression analysis revealed that bisoprolol significantly reduced the risk of re-hospitalization due to CHF and/or COPD exacerbation (unadjusted HR: 0.38; 95\% CI: 0.15-0.98; $P=0.046$ ) but carvedilol did not (Table 3). In the multivariate analysis, only a past history of COPD

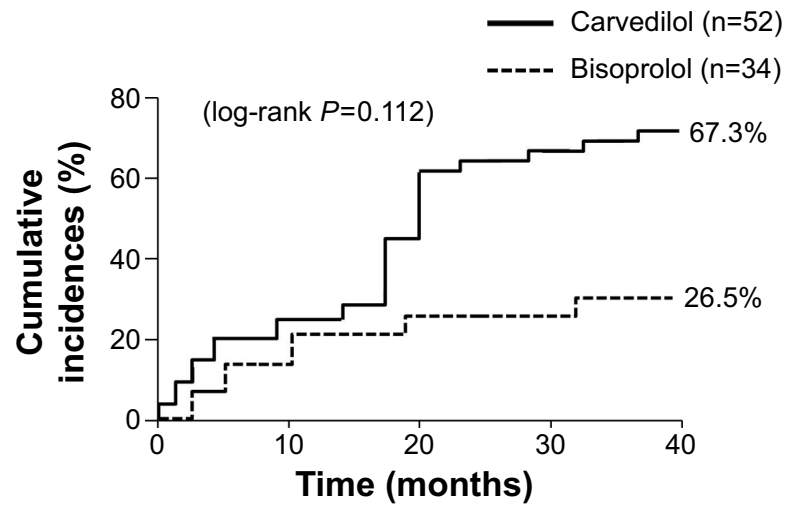

$\begin{array}{llllll}\text { Carvedilol } & 52 & 42 & 28 & 20 & 17 \\ \text { Bisoprolol } & 34 & 29 & 27 & 26 & 25\end{array}$

Figure 2 Cumulative incidence of all-cause death and CHF/COPD exacerbation. Note: No significant difference was observed between the carvedilol and bisoprolol groups (log-rank $P=0.112$ ).

Abbreviations: $\mathrm{CHF}$, congestive heart failure; COPD, chronic obstructive pulmonary disease.

exacerbation significantly increased the risk of rehospitalization due to CHF and/or COPD exacerbation (adjusted HR: 3.11; 95\% CI: 1.47-6.61; $P=0.003$ ) (Table 3). Table 4 presents the values of SBP, HR, LVEF, TRPG, BNP levels, and estimated GFR at baseline and at the 1-year follow-up. The 1-year changes in SBP, LVEF, TRPG, BNP levels, and estimated GFR were not significantly different between the two groups. However, the decrease in HR was greater in the bisoprolol group than in the carvedilol group.

\section{Discussion}

In the present study, we examined the effects of $\beta$-blockers in patients with $\mathrm{HF}$ and COPD. Approximately, $70 \%$ of the HF patients with COPD had received $\beta$-blockers, and these

Table 2 HRs for the risk of all-cause mortality

\begin{tabular}{|c|c|c|c|c|}
\hline & Unadjusted HR (95\% Cl) & $P$-value & Adjusted HR (95\% Cl) & $P$-value \\
\hline Age & $0.99(0.95-1.05)$ & 0.978 & & \\
\hline Male sex & $0.98(0.23-4.28)$ & 0.988 & & \\
\hline BMI & $0.97(0.85-I .10)$ & 0.652 & $0.94(0.78-1.12)$ & 0.478 \\
\hline Hypertension & $2.59(0.90-7.46)$ & 0.077 & $2.25(0.82-6.2 I)$ & 0.118 \\
\hline Atrial fibrillation & $2.98(0.94-9.39)$ & 0.063 & $2.32(0.78-6.89)$ & 0.130 \\
\hline$\beta$-blockers & $0.41(0.17-0.99)$ & 0.047 & $0.46(0.19-1.11)$ & 0.087 \\
\hline $\mathrm{BNP}(\geqq 300 \mathrm{pg} / \mathrm{mL})$ & $0.74(0.17-3.32)$ & 0.696 & $0.71(0.29-6.36)$ & 0.708 \\
\hline $\mathrm{EF}(<40 \%)$ & $1.59(0.42-6.04)$ & 0.479 & $\mathrm{I} .66(0.4 \mathrm{I}-6.70)$ & 0.472 \\
\hline ACE-I or ARB & $0.56(0.21-1.52)$ & 0.255 & $0.57(0.21-1.56)$ & 0.277 \\
\hline GOLD 3,4 & $0.82(0.35-1.92)$ & 0.652 & $0.75(0.31-1.80)$ & 0.511 \\
\hline Past history of COPD exacerbation & $1.59(0.84-3.02)$ & 0.158 & $1.82(0.90-3.67)$ & 0.093 \\
\hline Inhaled tiotropium & $0.42(0.15-1.15)$ & 0.090 & $0.42(0.15-1.18)$ & 0.099 \\
\hline
\end{tabular}

Abbreviations: $\mathrm{HR}$, hazard ratio; $\mathrm{Cl}$, confidence interval; BMI, body mass index; BNP, brain natriuretic peptide; EF, ejection fraction; ACE-I, angiotensin I converting enzyme inhibitor; ARB, angiotensin II receptor blocker; GOLD, global initiative for chronic obstructive lung disease; COPD, chronic obstructive pulmonary disease. 


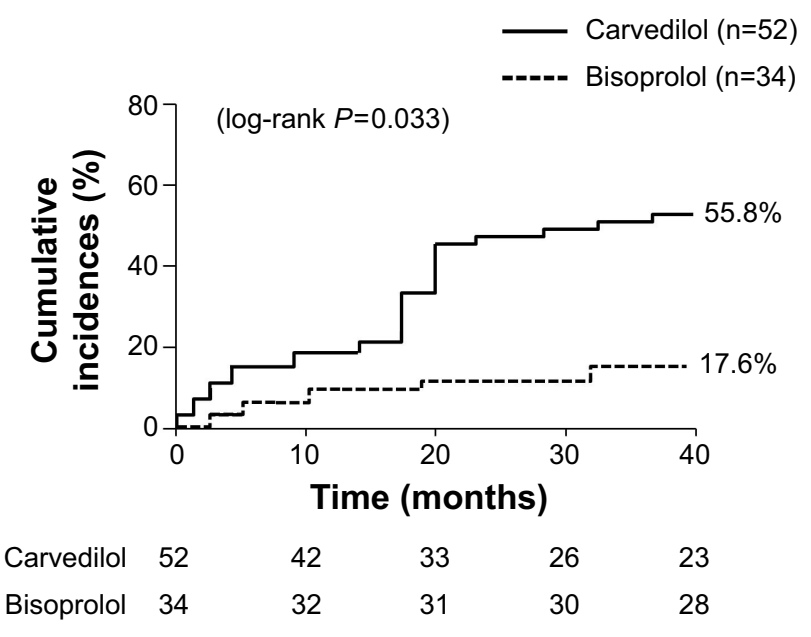

Figure 3 Cumulative incidence of CHF or COPD exacerbation.

Note: The event rate was higher in patients treated with carvedilol compared with those with bisoprolol (log-rank $P=0.033$ ).

Abbreviations: $\mathrm{CHF}$, congestive heart failure; COPD, chronic obstructive pulmonary disease.

were found to significantly reduce the all-cause mortality. Moreover, the baseline HR and EF before $\beta$-blocker administration were found to be higher in patients receiving bisoprolol compared with patients receiving carvedilol, whereas re-hospitalization due to $\mathrm{CHF}$ and/or COPD exacerbation occurred less frequently in patients receiving bisoprolol compared to patients receiving carvedilol.

Up to one-third of all deaths in patients with COPD can be attributable to cardiovascular disease, and, for every $10 \%$-decrease in the $\mathrm{FEV}_{1}$, the risk of cardiovascular mortality reportedly increases by $28 \%{ }^{26-28}$ The mechanistic links between COPD and cardiovascular disease are complex, multifactorial, and not entirely understood. Hyperinflation and increased falls in the intrathoracic pressure might compromise the ventricular preload and afterload, consequently leading to left ventricular dysfunction and acute heart failure. As most of these factors occur concurrently at the moment of acute exacerbation, these episodes are often associated with major cardiovascular events and high mortality. ${ }^{29}$ Despite increasing evidence that $\beta$-blockers are safe ${ }^{30,31}$ and can be beneficial in patients with COPD, their use continues to be limited in this group. This is a worldwide phenomenon ${ }^{32}$ and might be related to historical concerns that $\beta$-blockers could be harmful in patients with COPD, for example, by inducing bronchospasm. Such concerns, however, have been challenged by recent evidence, ${ }^{33}$ with several recent studies having advanced arguments in support of the use of $\beta$-blockers for COPD patients. ${ }^{34-38}$ One of these studies showed that $\beta$-blockers might reduce the risk of mortality and exacerbations in patients with COPD. ${ }^{34}$ Similarly, a systematic review and meta-analysis of nine retrospective cohort studies reported a reduction in COPD-related mortality of $31 \%$ after $\beta$-blocker use, ${ }^{39}$ and yet another study clearly showed the safety of $\beta$-blockers during COPD exacerbations. ${ }^{32}$ Moreover, the use of $\beta$-blockers when started either at the time of hospital admission for myocardial infarction or before a myocardial infarction has been demonstrated to be associated with improved survival after myocardial infarction in patients with COPD. ${ }^{40}$ In our study, similar to in these previous reports, $\beta$-blocker use was found to be associated with lower mortality compared to non- $\beta$-blocker use in CHF patients with COPD. Receiving $\beta$-blockers decreases the mortality rate through lowering the HR and through their sympatholytic effects, ${ }^{41}$ and $\beta$-blockers might benefit patients with HF and COPD, not only because of their effect on the CHF but also because they can affect the course of the COPD itself.

Regarding the different types of $\beta$-blockers, we here compared carvedilol, a typical non-selective $\beta$-adrenergic,

Table 3 HRs for the risk of COPD or CHF exacerbation

\begin{tabular}{|c|c|c|c|c|}
\hline & Unadjusted HR (95\% Cl) & $P$-value & Adjusted HR (95\% CI) & P-value \\
\hline Age & I.03 (0.97-I.09) & 0.363 & & \\
\hline Male sex & $0.76(0.23-2.54)$ & 0.660 & & \\
\hline BMI & $0.95(0.87-1.04)$ & 0.249 & $0.89(0.72-1.10)$ & 0.092 \\
\hline Hypertension & $2.05(0.84-5.00)$ & 0.114 & $1.47(0.63-3.43)$ & 0.379 \\
\hline Atrial fibrillation & $0.90(0.39-2.07)$ & 0.809 & $0.83(0.36-1.91)$ & 0.656 \\
\hline Bisoprolol & $0.38(0.15-0.98)$ & 0.046 & $0.47(0.18-1.24)$ & 0.126 \\
\hline BNP $(\geqq 300 \mathrm{pg} / \mathrm{mL})$ & $2.12(0.76-5.82)$ & 0.147 & I.9I (0.69-5.30) & 0.215 \\
\hline $\mathrm{EF}(<40 \%)$ & $2.09(0.79-5.52)$ & 0.136 & $2.10(0.79-5.54)$ & 0.135 \\
\hline ACE-I or ARB & $0.71(0.25-2.02)$ & 0.523 & $0.5 \mathrm{I}(0.20-\mathrm{I} .30)$ & 0.157 \\
\hline GOLD 3,4 & $0.75(0.26-2.22)$ & 0.607 & $0.62(0.20-1.94)$ & $0.4 \mid 4$ \\
\hline Past history of COPD exacerbation & $2.51(1.27-4.97)$ & 0.008 & $3.11(1.47-6.61)$ & 0.003 \\
\hline Inhaled tiotropium & $0.94(0.49-1.83)$ & 0.863 & $0.99(0.50-1.97)$ & 0.974 \\
\hline
\end{tabular}

Abbreviations: HR, hazard ratio; COPD, chronic obstructive pulmonary disease; CHF, congestive heart failure; $\mathrm{Cl}$, confidence interval; $\mathrm{BMI}$, body mass index; BNP, brain natriuretic peptide; EF, ejection fraction; ACE-I, angiotensin I converting enzyme inhibitor; ARB, angiotensin II receptor blocker; GOLD, global initiative for chronic obstructive lung disease. 
Table 4 Changes of the factors associated with heart failure

\begin{tabular}{|c|c|c|c|c|c|c|}
\hline \multirow[t]{2}{*}{ Variables } & \multicolumn{2}{|l|}{ Carvedilol } & \multirow[t]{2}{*}{$P$-value } & \multicolumn{2}{|l|}{ Bisoprolol } & \multirow[t]{2}{*}{$P$-value } \\
\hline & Baseline & Follow-up & & Baseline & Follow-up & \\
\hline $\mathrm{SBP}(\mathrm{mmHg})$ & $122.5 \pm 16.8$ & $120.3 \pm 10.7$ & 0.652 & $123.5 \pm 17.7$ & $|2| .4 \pm|| .4$ & 0.698 \\
\hline Heart rate (bpm) & $75.9 \pm 13.3$ & $70.6 \pm 9.7$ & 0.122 & $84.1 \pm 10.5$ & $70.3 \pm 10.3$ & $<0.05$ \\
\hline \multicolumn{7}{|l|}{ Data } \\
\hline eGFR $\left(\mathrm{mL} / \mathrm{min} / \mathrm{l} .73 \mathrm{~m}^{2}\right)$ & $54.5 \pm 21.1$ & $49.6 \pm 23.3$ & 0.533 & $56.8 \pm 13.2$ & $51.1 \pm 14.4$ & 0.364 \\
\hline $\mathrm{BNP}(\mathrm{pg} / \mathrm{mL})$ & $300.9 \pm 181.8$ & $248.0 \pm 273.8$ & 0.547 & $313.7 \pm 291.8$ & $230.7 \pm 224.8$ & 0.421 \\
\hline \multicolumn{7}{|l|}{ TTE } \\
\hline EF Simpson (\%) & $38.2 \pm 15.1$ & $41.8 \pm 11.4$ & 0.200 & $54.3 \pm 16.5$ & $57.1 \pm 18.8$ & 0.870 \\
\hline TRPG $(\mathrm{mmHg})$ & $32.2 \pm 15.2$ & $30.2 \pm 7.3$ & 0.437 & $43.9 \pm 27.6$ & $41.6 \pm 12.7$ & 0.756 \\
\hline
\end{tabular}

Note: Values are presented as means \pm SD, unless otherwise specified.

Abbreviations: SBP, systolic blood pressure; eGFR, estimated glomerular filtration rate; BNP, brain natriuretic peptide; TTE, trans-thoracic echocardiogram; EF, ejection fraction; TRPG, tricuspid regurgitation pressure gradient.

and $\alpha 1$-AR blocker with bisoprolol, a typical highly selective $\beta 1$-AR blocker, in order to determine which $\beta$-blocker is more appropriate for HF and COPD patients, a question that remains controversial. Bisoprolol is highly $\beta 1$-selective, providing a wide split between the $\beta 1$ - and $\beta 2$-adrenocepter blockades. ${ }^{42,43}$ Further, bisoprolol has recently been shown to be safe in patients with COPD. In a Cochrane database analysis, cardioselective $\beta$-blockers were demonstrated to not adversely affect the $\mathrm{FEV}_{1}$, respiratory symptoms, or the response of $\mathrm{FEV}_{1}$ to $\beta 2$ agonists. ${ }^{44}$ Conversely, it has been reported that carvedilol may aggravate pulmonary complications through blocking of the $\beta 2$ receptors, and its effects markedly differ between individuals due to different genetic polymorphisms, as compared with bisoprolol. ${ }^{45-47}$ Accordingly, switching from carvedilol to bisoprolol may provide beneficial effects with regard to the prognosis and/or reverse remodeling in patients who experience difficulty with the continuation or uptitration of carvedilol due to adverse effects such as dizziness or hypotension. ${ }^{48,49}$

Several studies have shown that the mortality benefits of carvedilol and other $\beta$-blockers are dose dependent, ${ }^{14,18,50}$ and the dose of carvedilol is moreover considered important for the management of cardiac sympathetic nerve activity. ${ }^{51}$ Cardioselective $\beta$-blockers are also dose dependent, ${ }^{5}$ and it is also recommended to use $\beta$-blockers that are more selective for the $\beta 1$-AR but without intrinsic sympathomimetic activity at the lowest dose and to titrate them slowly, while paying close attention to lung function and symptoms..$^{52}$ The doses of the two $\beta$-blockers used in our study were lower than the doses commonly used in many large-scale trials. However, trials on Japanese patients with HF have indicated that the $\mathrm{BP}$ and HR can be adequately decreased with the use of low doses of carvedilol and bisoprolol. ${ }^{18,53}$ These differences in the doses administered to Japanese patients and patients of other nationalities may be related to the pharmacological heterogeneity of $\beta$-blockers.

Furthermore, bisoprolol is less likely to cause bronchospasm compared to non-selective $\beta$-blockers, ${ }^{9}$ and the risk of bronchospasm can be further reduced by starting the $\beta$-blockers at a lower dose and slowly titrating up. In our study, the reduction in HR was more prominent in the bisoprolol group than in the carvedilol group at the 1-year follow-up. This result suggests that bisoprolol has a greater ability to suppress the HR of patients with HF and COPD than carvedilol, as the former is a highly selective $\beta 1$-AR blocker. In addition, treatment with bisoprolol was also associated with a significantly reduced risk of rehospitalization due to CHF and/or COPD exacerbation. On the other hand, in the sub-analysis of the OPTIMIZE-HF study, patients receiving non-cardioselective $\beta$-blockers had a lower event rate compared to patients receiving cardioselective $\beta$-blockers. ${ }^{22}$ However, it should be noted that, compared to the OPTIMIZE-HF study, the sample size and number of events of this study were relatively small, and rehospitalization due to COPD exacerbation was also included in the analyzed events, owning to difficulty in distinguishing CHF from COPD exacerbation. Furthermore, only bisoprolol was used as the cardioselective $\beta$-blocker in this study, whereas several different selective $\beta$-blockers were used in the OPTIMIZE-HF study.

Further, our results suggested that low doses of bisoprolol could also reduce the all-cause mortality in patients with $\mathrm{HF}$ and COPD, and it was moreover found to be associated with a significantly reduced risk of re-hospitalization due to CHF and/or COPD exacerbation compared with carvedilol. However, further prospective randomized controlled studies are needed to confirm our results and before initiation of $\beta$-blocker therapy to achieve a mortality benefit in COPD patients can be widely recommended. 


\section{Study limitations}

The main limitations of the present study were the relatively small number of enrolled patients and the retrospective study design. Moreover, the $\beta$-blockers were prescribed at discharge for the $\beta$-blocker group; at this time, the use of $\beta$-blockers was left at the discretion of the treating physicians. Therefore, the beneficial effects of the $\beta$-blockers in the present study can only be attributable to the time period of discharge, and we could not exclude the possibility that the addition and selection of the two $\beta$-blockers were made on the basis of the clinical status of the patients. The baseline EF was higher in patients receiving bisoprolol compared with patients receiving carvedilol; however, the EF did not significantly correlate with the incidence of CHF or COPD exacerbation in our study. Lastly, regarding the two $\beta$-blockers used in this study, different doses were prescribed, given that the equivalent dose of bisoprolol is only one-fifth that of carvedilol. ${ }^{54,55}$ Although most confounders were included in the multivariate regression analysis, it is nonetheless possible that some potential bias exists, and large-scale, prospective randomized controlled trials are needed in the future to clarify the effects of $\beta$-blockers in patients with HF and COPD.

\section{Conclusion}

Our findings support the recommendations to use $\beta$-blockers in HF patients with COPD. The use of a selective $\beta$-blocker reduced the incidence of $\mathrm{CHF}$ and/or COPD exacerbation compared with non-selective $\beta$-blocker use in the univariate analyses in the present study; however, after controlling for other variables, the effect of $\beta$-blockers ceased to be significant. Further studies with longer duration and larger numbers of $\mathrm{HF}$ and COPD patients are needed to confirm whether there are any differences between the effects of the two types of $\beta$-blockers on HF and COPD improvement.

\section{Disclosure}

The authors declare that they have no competing interests.

\section{References}

1. Lainscak M, Cleland JG, Lenzen MJ, Follath F, Komajda M, Swedberg K International variations in the treatment and co-morbidity of left ventricular systolic dysfunction: data from the EuroHeart Failure Survey. Eur J Heart Fail. 2007;9:292-299.

2. Hawkins NM, Petrie MC, Jhund PS, Chalmers GW, Dunn FG, McMurray JJ. Heart failure and chronic obstructive pulmonary disease: diagnostic pitfalls and epidemiology. Eur J Heart Fail. 2009;11:130-139.

3. Sin DD, McAlister FA. The effects of beta-blockers on morbidity and mortality in a population-based cohort of 11,942 elderly patients with heart failure. Am J Med. 2002;113:650-656.

4. Komajda M, Follath F, Swedberg K, et al. The EuroHeart Failure Survey programme - a survey on the quality of care among patients with heart failure in Europe. Part 2: treatment. Eur Heart J. 2003;24: 464-474.
5. Hawkins NM, Petrie MC, Macdonald MR, et al. Heart failure and chronic obstructive pulmonary disease the quandary of Beta-blockers and Beta-agonists. J Am Coll Cardiol. 2011;57:2127-2138.

6. Dickstein K, Cohen-Solal A, Filippatos G, et al. ESC Guidelines for the diagnosis and treatment of acute and chronic heart failure 2008: the Task Force for the Diagnosis and Treatment of Acute and Chronic Heart Failure 2008 of the European Society of Cardiology. Developed in collaboration with the Heart Failure Association of the ESC (HFA) and endorsed by the European Society of Intensive Care Medicine (ESICM). Eur Heart J. 2008;29:2388-2442.

7. Al-Mohammad A, Mant J. The diagnosis and management of chronic heart failure: review following the publication of the NICE guidelines. Heart. 2011;97:411-416.

8. Gottlieb SS, McCarter RJ, Vogel RA. Effect of beta-blockade on mortality among high-risk and low-risk patients after myocardial infarction. N Engl J Med. 1998;339:489-497.

9. Galatius S, Gustafsson F, Atar D, Hildebrandt PR. Tolerability of beta-blocker initiation and titration with bisoprolol and carvedilol in congestive heart failure - a randomized comparison. Cardiology. 2004; 102:160-165.

10. Jabbour A, Macdonald PS, Keogh AM, et al. Differences between betablockers in patients with chronic heart failure and chronic obstructive pulmonary disease: a randomized crossover trial. J Am Coll Cardiol. 2010;55:1780-1787.

11. Lainscak M, Podbregar M, Kovacic D, Rozman J, von Haehling S. Differences between bisoprolol and carvedilol in patients with chronic heart failure and chronic obstructive pulmonary disease: a randomized trial. Respir Med. 2011;105(suppl 1):S44-S49.

12. Ni Y, Shi G, Wan H. Use of cardioselective beta-blockers in patients with chronic obstructive pulmonary disease: a meta-analysis of randomized, placebo-controlled, blinded trials. J Int Med Res. 2012;40:2051-2065.

13. Loth DW, Brusselle GG, Lahousse L, Hofman A, Leufkens HG, Stricker BH. Beta-Adrenoceptor blockers and pulmonary function in the general population: the Rotterdam Study. Br J Clin Pharmacol. 2014; 77:190-200.

14. Bristow MR, Gilbert EM, Abraham WT, et al. Carvedilol produces dose-related improvements in left ventricular function and survival in subjects with chronic heart failure. MOCHA Investigators. Circulation. 1996;94:2807-2816.

15. Packer M, Bristow MR, Cohn JN, et al. The effect of carvedilol on morbidity and mortality in patients with chronic heart failure. U.S. Carvedilol Heart Failure Study Group. N Engl J Med. 1996;334:1349-1355.

16. Packer M, Fowler MB, Roecker EB, et al; Carvedilol Prospective Randomized Cumulative Survival (COPERNICUS) Study Group. Effect of carvedilol on the morbidity of patients with severe chronic heart failure: results of the carvedilol prospective randomized cumulative survival (COPERNICUS) study. Circulation. 2002;106:2194-2199.

17. Poole-Wilson PA, Swedberg K, Cleland JG, et al; Carvedilol Or Metoprolol European Trial Investigators. Comparison of carvedilol and metoprolol on clinical outcomes in patients with chronic heart failure in the Carvedilol Or Metoprolol European Trial (COMET): randomised controlled trial. Lancet. 2003;362:7-13.

18. Hori M, Sasayama S, Kitabatake A, et al; MUCHA Investigators. Low-dose carvedilol improves left ventricular function and reduces cardiovascular hospitalization in Japanese patients with chronic heart failure: the Multicenter Carvedilol Heart Failure Dose Assessment (MUCHA) trial. Am Heart J. 2004;147:324-330.

19. A randomized trial of beta-blockade in heart failure. The Cardiac Insufficiency Bisoprolol Study (CIBIS). CIBIS Investigators and Committees. Circulation. 1994;90:1765-1773.

20. The Cardiac Insufficiency Bisoprolol Study II (CIBIS-II): a randomised trial. Lancet. 1999;353:9-13.

21. Willenheimer R, van Veldhuisen DJ, Silke B, et al; CIBIS III Investigators. Effect on survival and hospitalization of initiating treatment for chronic heart failure with bisoprolol followed by enalapril, as compared with the opposite sequence: results of the randomized Cardiac Insufficiency Bisoprolol Study (CIBIS) III. Circulation. 2005;112:2426-2435. 
22. Mentz RJ, Wojdyla D, Fiuzat M, Chiswell K, Fonarow GC, O'Connor CM. Association of beta-blocker use and selectivity with outcomes in patients with heart failure and chronic obstructive pulmonary disease (from OPTIMIZE-HF). Am J Cardiol. 2013;111:582-587.

23. McKee PA, Castelli WP, McNamara PM, et al. The natural history of congestive heart failure: the Framingham study. N Engl J Med. 1971; 285:1441-1446.

24. Rabe KF, Hurd S, Anzueto A, et al; Global Initiative for Chronic Obstructive Lung Disease. Global strategy for the diagnosis, management, and prevention of chronic obstructive pulmonary disease: GOLD executive summary. Am J Respir Crit Care Med. 2007;176:532-555.

25. Levey AS, Bosch JP, Lewis JB, Greene T, Rogers N, Roth D. A more accurate method to estimate glomerular filtration rate from serum creatinine: a new prediction equation. Modification of Diet in Renal Disease Study Group. Ann Intern Med. 1999;130:461-470.

26. Mannino DM, Thorn D, Swensen A, Holguin F. Prevalence and outcomes of diabetes, hypertension and cardiovascular disease in COPD. Eur Respir J. 2008;32:962-969.

27. Zielinski J, MacNee W, Wedzicha J, et al. Causes of death in patients with COPD and chronic respiratory failure. Monaldi Arch Chest Dis. 1997;52:43-47.

28. Anthonisen NR, Connett JE, Murray RP. Smoking and lung function of Lung Health Study participants after 11 years. Am J Respir Crit Care Med. 2002;166:675-679.

29. Holguin F, Folch E, Redd SC, Mannino DM. Comorbidity and mortality in COPD-related hospitalizations in the United States, 1979 to 2001. Chest. 2005;128:2005-2011.

30. Dransfield MT, Rowe SM, Johnson JE, Bailey WC, Gerald LB. Use of beta blockers and the risk of death in hospitalised patients with acute exacerbations of COPD. Thorax. 2008;63:301-305.

31. Short PM, Lipworth SI, Elder DH, et al. Effect of beta blockers in treatment of chronic obstructive pulmonary disease: a retrospective cohort study. BMJ. 2011;342:d2549.

32. Stefan MS, Rothberg MB, Priya A, Pekow PS, Au DH, Lindenauer PK. Association between beta-blocker therapy and outcomes in patients hospitalised with acute exacerbations of chronic obstructive lung disease with underlying ischaemic heart disease, heart failure or hypertension. Thorax. 2012;67:977-984.

33. Albouaini K, Andron M, Alahmar A, et al. Beta-blockers use in patients with chronic obstructive pulmonary disease and concomitant cardiovascular conditions. Int J Chron Obstruct Pulmon Dis. 2007;2:535-540.

34. Rutten FH, Zuithoff NP, Hak E, Grobbee DE, Hoes AW. Beta-blockers may reduce mortality and risk of exacerbations in patients with chronic obstructive pulmonary disease. Arch Intern Med. 2010;170:880-887.

35. Farland MZ, Peters CJ, Williams JD, Bielak KM, Heidel RE, Ray SM. Beta-Blocker use and incidence of chronic obstructive pulmonary disease exacerbations. Ann Pharmacother. 2013;47:651-656.

36. Zeng LH, Hu YX, Liu L, Zhang M, Cui H. Impact of beta2-agonists, beta-blockers, and their combination on cardiac function in elderly male patients with chronic obstructive pulmonary disease. Clin Interv Aging. 2013;8:1157-1165.

37. Puente-Maestu L, Calle M, Ortega-González A, et al; GEMEPOC Group. Multicentric study on the beta-blocker use and relation with exacerbations in COPD. Respir Med. 2014;108:737-744.

38. Du Q, Sun Y, Ding N, Lu L, Chen Y. Beta-blockers reduced the risk of mortality and exacerbation in patients with COPD: a meta-analysis of observational studies. PLoS One. 2014;9:e113048.

39. Etminan M, Jafari S, Carleton B, FitzGerald JM. Beta-blocker use and COPD mortality: a systematic review and meta-analysis. BMC Pulm Med. 2012;12:48.
40. Quint JK, Herrett E, Bhaskaran K, et al. Effect of beta blockers on mortality after myocardial infarction in adults with COPD: population based cohort study of UK electronic healthcare records. $B M J$. 2013;347:f6650.

41. Lechat P, Hulot JS, Escolano S, et al. Heart rate and cardiac rhythm relationships with bisoprolol benefit in chronic heart failure in CIBIS II Trial. Circulation. 2001;103:1428-1433.

42. Dorow P, Bethge H, Tonnesmann U. Effects of single oral doses of bisoprolol and atenolol on airway function in nonasthmatic chronic obstructive lung disease and angina pectoris. Eur J Clin Pharmacol. 1986;31:143-147.

43. Macquin-Mavier I, Roudot-Thoraval F, Clerici C, George C, Harf A. Comparative effects of bisoprolol and acebutolol in smokers with airway obstruction. Br J Clin Pharmacol. 1988;26:279-284.

44. Salpeter S, Ormiston T, Salpeter E. Cardioselective beta-blockers for chronic obstructive pulmonary disease. Cochrane Database Syst Rev. 2005:CD003566.

45. Nozawa T, Taguchi M, Tahara K, et al. Influence of CYP2D6 genotype on metoprolol plasma concentration and beta-adrenergic inhibition during long-term treatment: a comparison with bisoprolol. J Cardiovasc Pharmacol. 2005;46:713-720.

46. Taguchi M, Nozawa T, Igawa A, et al. Pharmacokinetic variability of routinely administered bisoprolol in middle-aged and elderly Japanese patients. Biol Pharm Bull. 2005;28:876-881.

47. Honda M, Ogura Y, Toyoda W, et al. Multiple regression analysis of pharmacogenetic variability of carvedilol disposition in 54 healthy Japanese volunteers. Biol Pharm Bull. 2006;29:772-778.

48. Nul D, Zambrano C, Diaz A, et al; Grupo de Estudio de la Sobrevida en la Insuficiencia Cardiaca en Argentina. Impact of a standardized titration protocol with carvedilol in heart failure: safety, tolerability, and efficacy-a report from the GESICA registry. Cardiovasc Drugs Ther. 2005;19:125-134.

49. Taniguchi T, Ohtani T, Mizote I, et al. Switching from carvedilol to bisoprolol ameliorates adverse effects in heart failure patients with dizziness or hypotension. J Cardiol. 2013;61:417-422.

50. Simon T, Mary-Krause M, Funck-Brentano C, et al. Bisoprolol doseresponse relationship in patients with congestive heart failure: a subgroup analysis in the cardiac insufficiency bisoprolol study (CIBIS II). Eur Heart J. 2003;24:552-559.

51. Nishiyama K, Tsutamoto T, Yamaji M, et al. Dose-dependent prognostic effect of carvedilol in patients with chronic heart failure - special reference to transcardiac [corrected] gradient of norepinephrine. Circ J. 2009; 73:2270-2275.

52. Matera MG, Martuscelli E, Cazzola M. Pharmacological modulation of beta-adrenoceptor function in patients with coexisting chronic obstructive pulmonary disease and chronic heart failure. Pulm Pharmacol Ther. 2010;23:1-8.

53. Konishi M, Haraguchi G, Kimura S, et al. Comparative effects of carvedilol vs bisoprolol for severe congestive heart failure. Circ J. 2010;74:1127-1134.

54. Düngen HD, Apostolovic S, Inkrot S, et al; CIBIS-ELD investigators and Project Multicentre Trials in the Competence Network Heart Failure. Titration to target dose of bisoprolol vs carvedilol in elderly patients with heart failure: the CIBIS-ELD trial. Eur J Heart Fail. 2011;13:670-680.

55. Di Lenarda A, Remme WJ, Charlesworth A, COMET Investors, et al. Exchange of beta-blockers in heart failure patients. Experiences from the poststudy phase of COMET (the Carvedilol or Metoprolol European Trial). Eur J Heart Fail. 2005;7:640-649. 
International Journal of COPD

\section{Publish your work in this journal}

The International Journal of COPD is an international, peer-reviewed journal of therapeutics and pharmacology focusing on concise rapid reporting of clinical studies and reviews in COPD. Special focus is given to the pathophysiological processes underlying the disease, intervention programs, patient focused education, and self management protocols.

This journal is indexed on PubMed Central, MedLine and CAS. The manuscript management system is completely online and includes a very quick and fair peer-review system, which is all easy to use. Visit http://www.dovepress.com/testimonials.php to read real quotes from published authors 